\title{
Genetic Relationship Among Ten Promising Eggplant Varieties Using RAPD Markers
}

\section{Md. Sanaullah Biswas*, Md. Abdullah Yousuf Akhond, Md. Al-Amin, Mahmuda Khatun and Muhammed Rezwan Kabir}

Biotechnology Division, Bangladesh Agricultural Research Institute (BARI), Gazipur-1701, Bangladesh

Key words: Eggplant, Polymorphism, Genetic relationship, RAPD

\begin{abstract}
RAPD technique was used as a tool for assessing genetic diversity and varietal relationships among ten varieties of eggplant. Out of 21 primers screened four were selected. With these primers 76 clear and bright fragments were obtained of which 44 fragments considered polymorphic. The proportion of polymorphic loci and gene diversity values across all loci were $57.89 \%$ and 0.23 , respectively. The UPGMA dendrogram based on genetic distance segregated the ten varieties of eggplant into two main clusters. Dohazari, Kazla, Nayantara and ISD-006 were grouped together in cluster I whereas Uttara, Islampuri, Khatkhatia, Singnath, BARI Begun-08 and Eggplant Line-083 into cluster II. Kazla and Nayantara variety pair was very close to each other with the highest intervarietal similarity index (92.54\%) and lowest genetic distance (0.14). On the other hand, Khatkhatia and Nayantara pair was the lowest intervarietal similarity index $(41.67 \%)$ with highest genetic distance (0.48). Therefore, identification of genetically distinct varieties using RAPD markers could be a potential tool for eggplant improvement.
\end{abstract}

\section{Introduction}

Eggplant or brinjal (Solanum melongena L.) is widely cultivated as a vegetable crop in both temperate and tropical areas. In Bangladesh, eggplant is one of the important vegetable crops grown round the year in every corners of the country. The origin of this vegetable was the Indian subcontinent. Hundreds of cultivars with many wild types are available in this area (Sing et al. 2001). Information concerning the extent and nature of genetic diversity within a crop species is essential for an effective breeding programme. It is particularly useful for characterizing individual genotypes and selection of the parents for successful hybridization. Several workers have contributed to the characterization of the largest genus Slanum of Solanaceae (Furini and Wunder 2004, Correll 1962, Seithe

*Author for correspondence. <msbiswal332@yahoo.com> 
and Anderson 1982, Whalen 1984, Bohs 1999). Genetic fingerprinting has been accomplished traditionally by the use of isozymes, total seed protein and more recently with various types of molecular markers. DNA-based markers provide powerful tools for assessing variations within crop germplasm (Gepts 1993). Among molecular markers, random amplified polymorphic DNAs (RAPDs) have been extensively using in genetic research owing to their speed and simplicity (Williams et al. 1990). Most of the variability/taxonomic affinity studies in eggplant have focused mainly on morphology, crossability, anatomy, isozyme and chloroplast DNA diversity. However, morphological traits have certain limitations such as easily available of scorable markers, difficulty in scoring homozygous from heterozygous individuals, influence of environment in equating phenotypes with genotypes etc. On the other hand, molecular markers have many advantages such as abundance in polymorphism, no pleiotropic effect, less affected by environment and subjected to rapid detection (Sing et al. 2005). RAPD has been using extensively for studying genetic diversity of crops in different parts of the world. However, no report on RAPD is available regarding the diversity of eggplant in Bangladesh. Karihaloo and Gottlieb (1995) carried out RAPD analysis of 52 accessions of Solanum melongena and a related weedy form S. insanum. They reported greater DNA polymorphism in the weedy species than in the advanced cultivars. Identification of distinct characters at DNA level would be useful for varietal improvement or hybrid seed production. Phylogenetic relationships among taxa have been established previously considering mainly the morphological features, crossability and $F_{1}$ fertility (Lester and Hasan 1991). Establishing genetic affinities based on such parameters are insufficient. To overcome these problems isozyme was used as a tool but met with little success (Deb 1989). Therefore, present study was aimed at analysing ten promising eggplant varieties of Bangladesh for establishing the relationship and variability using RAPD data.

\section{Materials and Methods}

Nine promising eggplant varieties released by Bangladesh Agricultural Research Institute (BARI) and one advanced line were used in this study at the Biotechnology Division, BARI, Gazipur. Dohazari, ISD-006, Uttara, Kazla, Nayantatara, Islampuri, Singnath, Khatkhatia, BARI Begun-08, Eggplant Line083, were collected from Horticulature Research Centre, BARI, Gazipur. Total genomic DNA from young leaves of young plants were isolated following choloroform : isoamyl alcohol purification and propanol precipitation method (Doyle and Doyle 1987). The isolated samples were stored at $-20^{\circ} \mathrm{C}$. DNA concentrations were determined at $260 \mathrm{~nm}$ with spectrophotomer (NanoDrop) 
and the quality verified by electrophoresis on 1\% agarose gel in TAE (Trisacetate-EDTA) buffer.

PCR conditions were optimized by varying the concentrations of template DNA, Taq DNA polymerase and $\mathrm{MgCl}_{2}$ concentration. Initial screening was done with 10-mer primers (Operon Technologies Inc., USA) using DNA from each genomic DNA sample. The primers (Table 1) that gave reproducible and scorable amplifications were used in the analysis of all the ten varieties.

Table 1. Selected primers along with their sequence and some characteristics of amplification products in the eggplant varieties.

\begin{tabular}{llcccc}
\hline Primers & $\begin{array}{l}\text { Sequence } \\
\text { 5'to 3' }\end{array}$ & $\begin{array}{c}\text { No. of } \\
\text { bands }\end{array}$ & $\begin{array}{c}\text { Mo. wt. } \\
\text { range }(\mathrm{Kb})\end{array}$ & $\begin{array}{c}\text { No. of mono- } \\
\text { morphic bands }\end{array}$ & $\begin{array}{c}\text { No. of poly- } \\
\text { morphic bands }\end{array}$ \\
\hline OPA-01 & CAGGCCCTTC & 22 & $0.1-3.0$ & 11 & 11 \\
OPA-09 & GGGTAACGCC & 21 & $0.1-3.0$ & 11 & 10 \\
OPB-01 & GTTTCGCTCC & 20 & $0.1-3.0$ & 6 & 14 \\
OPC-05 & GATGACCGCC & 13 & $0.1-3.0$ & 4 & 9 \\
Total & & 76 & & 32 & 44 \\
Av. & 19 & & 8 & 11 \\
\hline
\end{tabular}

Total reaction volume for DNA amplification was $25 \mathrm{ml}$. A reaction mixture contained 1X PCR buffer (10 mM Tris $\mathrm{HCl}, \mathrm{pH} 8.8,50 \mathrm{mM} \mathrm{KCl}$ and $15 \mathrm{mM}$ $\left.\mathrm{MgCl}_{2}\right), 2 \mathrm{mM}$ each dNTPs, 10 pmols primer, 5 unit of Taq DNA polymerase and $100 \mathrm{ng}$ of genomic DNA. DNA amplification was performed (Thermal Cycler, Eppendrop) as follows: 1 cycle of $3 \mathrm{~min}$ at $94^{\circ} \mathrm{C}$ (initial strand separation) followed by 45 cycles each of $1 \mathrm{~min}$ at $94^{\circ} \mathrm{C}$ (denatuartaion), $1 \mathrm{~min}$ at $36^{\circ} \mathrm{C}$ (annealing) and $2 \mathrm{~min}$ at $72^{\circ} \mathrm{C}$ (primer extension) after the last cycle, a final step of 7 minutes at $72^{\circ} \mathrm{C}$ was added to allow complete extension of all amplified fragments. After amplification, PCR products were stored at $4^{\circ} \mathrm{C}$ untill electrophoresis. Reaction products were mixed with $2.5 \mu$ l of 10X loading dye (Sambrook et al. 1989) and spin briefly in a microcentrifuge before loading. PCR products were resolved by electrophoresis at $1.4 \%$ agarose gel, $80 \mathrm{~V}$ for $2 \mathrm{hr}$ followed by staining with ethidium bromide. Gels were photographed in Gel Documentation System (Alphainnotech, USA). Since RAPD markers are dominant, it is assumed that each band represented the phenotype at a single allelic locus (Williams et al. 1990). All distinct bands or fragments (RAPD markers) were thereby given identification numbers according to their position on gel and scored visually on the basis of their presence (1) or absence (0), separately for each individual and each primer. The scores obtained using all the primers in the RAPD analysis were then pooled to create a single data matrix, to estimate polymorphic loci, gene diversity, genetic distance (D) and to construct a UPGMA (Unweighted Pair Group Method of Arithmetic Means) dendrogram 
among populations using a computer program, POPGENE (Version 1.31) (Yeh et al. 1999).

Genetic similarity values defined as the fraction of shared bands between the RAPD profiles of any two individuals on the same gel were calculated manually from RAPD markers of the same weight on the data matrix.

Similarity index (SI) was calculated from $2 n_{x y} / n_{x}+n_{y}$, when $n_{x y}$ is the number of the common DNA bands in $\mathrm{x}$ and $\mathrm{y}$ plants, $\mathrm{n}_{\mathrm{x}}$ and $\mathrm{n}_{\mathrm{y}}$ are the total DNA bands of $X$ and Y plant, respectively (Hill et al. 1996).

\section{Results and Discussion}

The RAPD analysis carried out on the ten varieties produced a large number of distinct fragments for each primer. Four arbitrary primers were selected after screening. These generated a total of 76 scorable bands of which 44 were polymorphic, with an average of 19 amplicons per primer. Sadder et al. (2004) reported nine primers showing polymorphism in 81 of 85 bands amplified. The numbers of amplification products obtained were in the range of $13-22$ with the primer OPC-05 producing the minimum (13) (Table 1) and the primer OPA-01 producing the maximum (22) number of bands (Fig. 1). On an average 19 bands were obtained per primer with a range of $0.10-3.0 \mathrm{~kb}$. The primer OPB-01 produced the highest number (14) of polymorphic bands. The percentage of polymorphic loci was 57.89 indicates a higher level of polymorphism. On the other hand, the primer OPA-01, OPA-09 and OPC-05 generated 11, 10 and 9 polymorphic bands, respectively. These results gave an average of 11 polymorphic bands per primer (Table 1 ).

The intervariety similarity indices within the ten eggplant varieties ranged from 41.67 to $92.54 \%$. Sing et al. (2005) observed the level of polymorphism among 28 eggplant accessions was 0.05 - 0.82, indicating a wide and diverse base. Karihaloo and Gottlieb (1995) reported similarity of 52 accessions of Solanum and found highest similarity (0.947) between S. insanum and S. melongena. Pair-wise variety comparison of the varieties showed that inter-cultivar similarity indices for Kazla vs. Nayantara (92.54), for Singnath vs. BARI Begun-08 (91.07) were higher than all other cultivar pairs. On the other hand, inter-cultivar similarity index for Khatkhatia vs. BARI Eggplant Line-083 (41.67) cultivar was lower than all the other cultivar pairs. Among 10 Jordanian eggplant landraces E22 and E23 showed highest distant similarity $80.5 \%$ while the most distant genotypes were E12 and Ec5 having lowest similarity 4.8\% (Sadder et al. 2004).

Dendrogram based on Nei's (1972) genetic distance UPGMA indicated segregation of the ten eggplant varieties into two main clusters. Dohazari, Kazla, Nayantara and ISD-006 were grouped together in cluster I whereas Uttara, 
Islampuri, Khatkhatia, Singnath, BARI Begun-08 and Eggplant Line-083 in cluster II. In cluster I, ISD-006 alone formed sub cluster II and Dohazari, Kazla and Nayantara formed together sub cluster II. In cluster II, Uttara, Islampuri, Khatkhatia and Singnath, BARI Begun-08 and Eggplant Line-083 formed sub
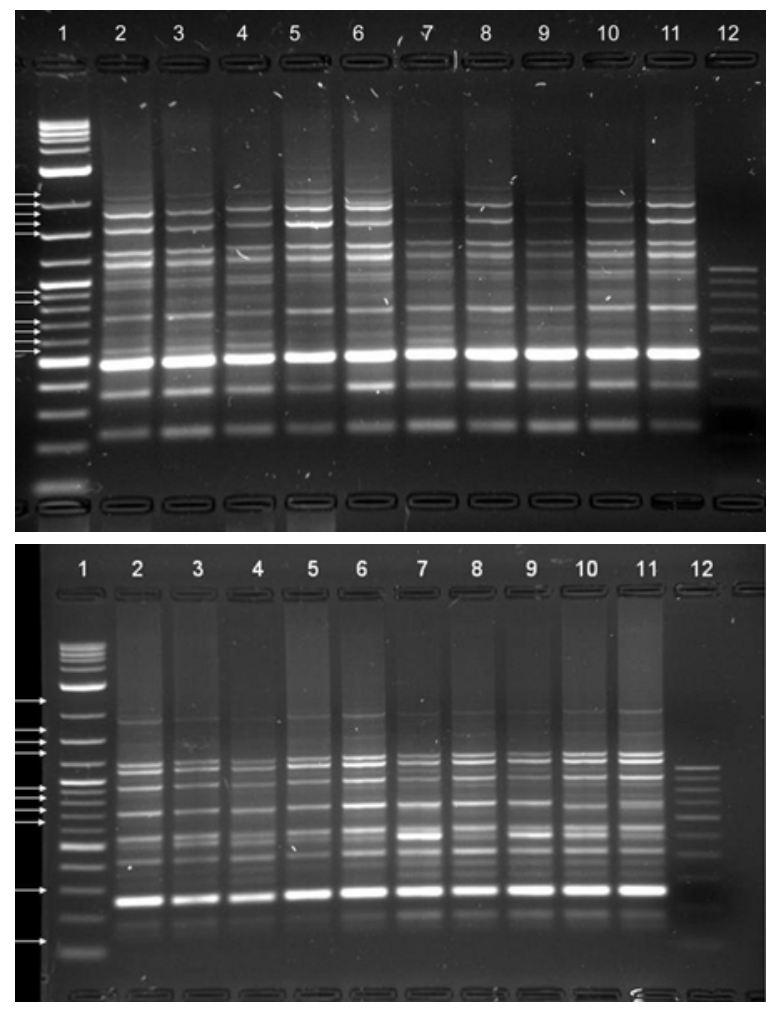

Fig. 1. RAPD profiles for ten promising eggplant varieties by primers OPA-01 (top) OPA-09 (bottom); Lane 1: 2-log ladder, Lane 2: Dohazari, Lane 3: ISD-006, Lane 4: Uttara, Lane 5: Kazla, Lane 6: Nayantara, Lane 7: Islampuri, Lane 8: Singnath, Lane 9: Khatkhatia, Lane 10: BARI Begun-08, Lane 11: Eggplant Line-083, Lane 12: 100 bp ladder. Arrows indicate polymorphic bands.

cluster I and sub cluster II, respectively. Again in cluster I, Dohazari alone formed sub sub cluster I and Kazla and Nayantara sub sub cluster II. In cluster II, Khatkhatia and Eggplant Line-083 individually formed sub sub cluster II and Uttara, Islampuri and Singnath, Eggplant-08 formed sub sub cluster I. In sub sub clusters I and II, Kazla-Nayantara, Uttara-Islampuri and Singnath-BARI Begun08 grouped separately with lower level of genetic distance $0.14,0.16$ and 0.17 , respectively (Table 2). A highest level of genetic distance was observed between Nayantara and Khatkhatia and lowest level of genetic distance showed between Kazla and Nayantara with 0.48 and 0.14, respectively (Table 2). Nayantara, Khatkhatia and Eggplant Line-083 separately formed sub sub clusters with their respective sub sub cluster. 


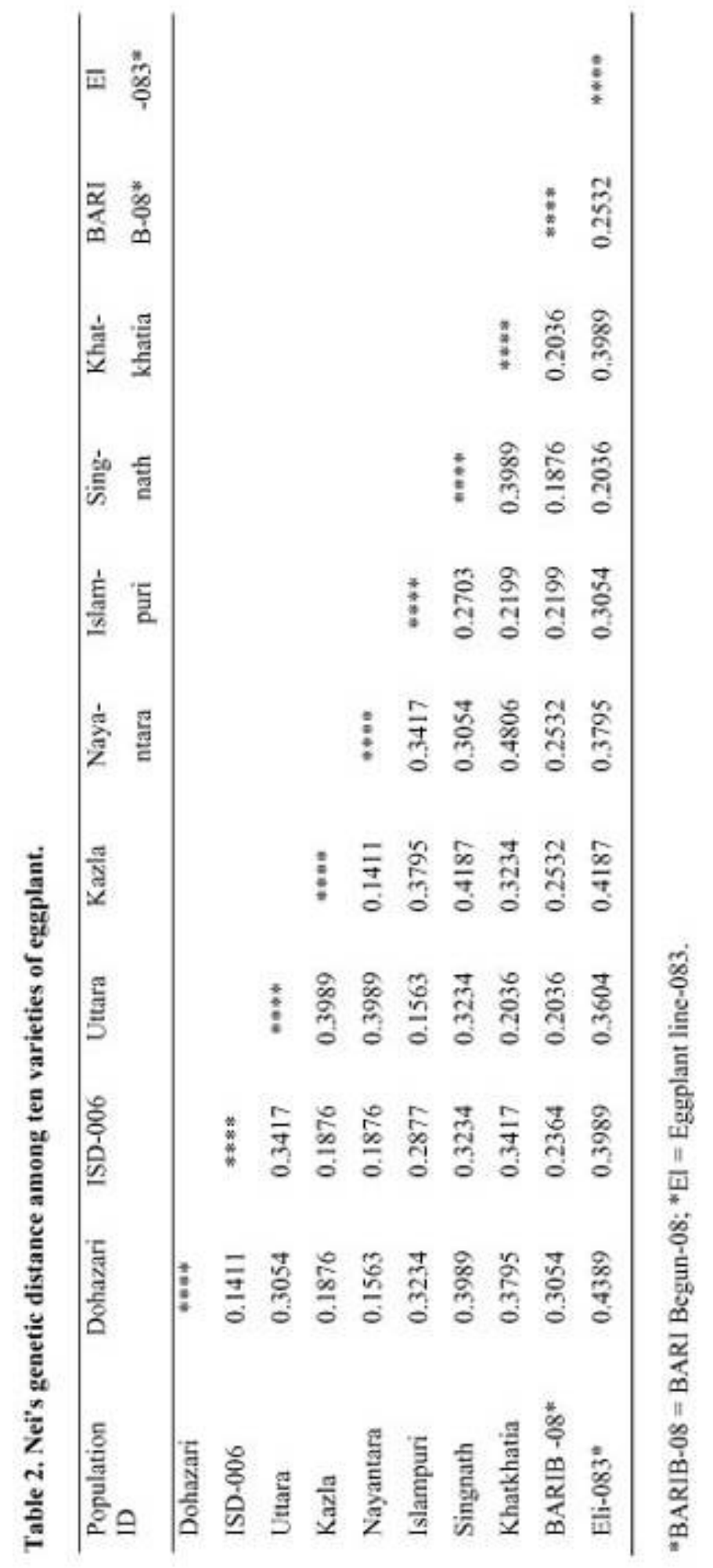




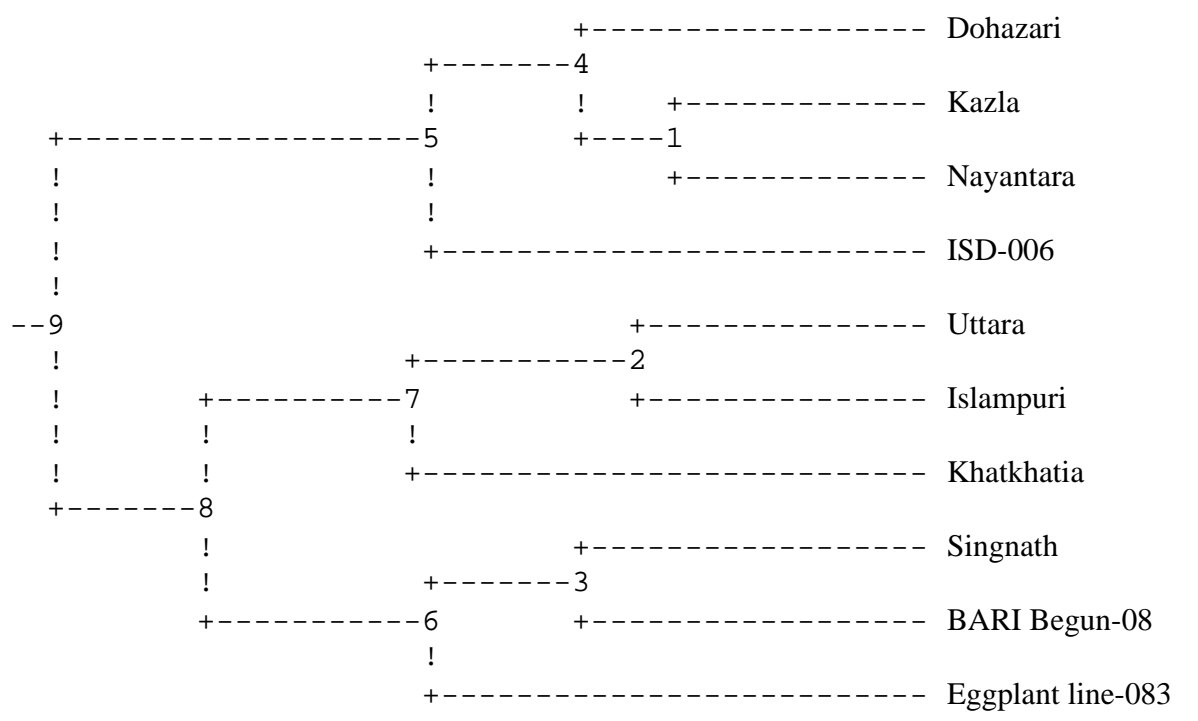

Fig. 2. UPGMA cluster analysis-based dendrogram showing genetic relationship among ten varieties of eggplant.

Observed and effective numbers of alleles of all the varieties were 1.58 and 1.40 , respectively. Nei's genetic diversity of the varieties was 0.23 . So for the hybridization or varietal development Nayantara and Kazla or Khatkhatia and Nayantara may be a good combination based on the DNA variability using RAPD markers.

\section{References}

Bohs I (1999) Cyphomandra (Solanaceae) Flora Neotropica Monograph.. 63, New York Botanical Garden.

Correll DS (1962) The potato and its wild relatives. Contribution of Texas Research Foundation. Bot. Stud. S4: 1-606.

Deb DB (1989) Solanum melongena versus S. incanum (Solanaceae). Taxon. 38: 138-139.

Doyle JJ and Doylle JL (1987) A rapid DNA isolation procedure for small quantities of fresh leaf tissue. Phytoche. Bull. 19: 119-128.

Furini A and Wunder J (2004) Analysis of eggplant (Solanum melongena) related germplasm: morphological and AFLP data contribute to phylogenetic interpretations and germplasm utilization. Theor. Appl. Genet. 108: 197-208.

Gepts P (1993) The use of molecular and biochemical markers in crop evolution studies. Evol. Biol. 27: 51-94.

Hill DM, Moriz C and Mable BK (1996) Molecular Systematics. $2^{\text {nd }}$ eds. Sinasuer Associates. Massachusettes.

Karihaloo JL and Gottlieb LD (1995) Random amplified polymorphic variation in the eggplant, Solanum melongena L. (Solanaceae). Theor. Appl. Genet. 90: 767-770. 
Lester RN and Hasan SMZ (1991) Origin and domestication of the eggplant eggplant Solanum melongena from S. incanum in Africa and Asia. In Solanaceae III. Taxonomy, Chemistry, Evolution (eds Hawakes, J. G., Lester, R. N., Nee, M. and Estrada, N.), The Royal Botanic Gardens, Kew, London, pp. 369-388.

Nei M (1972) Genetic distance between populations. Amer. Nat. 106: 283-292.

Sadder MT, Al-Shareef RM and Handan H (2004) Assessment of genetic, morphological and agronomical diversity among Jordanian eggplant (Solanum melongena L.) landraces using Random Amplified Polymorphic DNA (RAPD), ISHS Acta Horticulturae 745: VI International Solanaceae Conference: Genomics meets Biodiversity.

Sambrook JE, Fritch F and Maniatis T (1989) Molecular Cloning -A Laboratory Manual 2nd edn, Cold Spring Harbor Laboratory, New York, USA.

Seithe A and Anderson GJ (1982) Hair morphology and the relationships of species in Solanum sect. Basarthun. Plant. Sits. Evol. 139: 229-256.

Sing A, Borthakur A and Deka PC (2001) Biotechnology of Horticultural Crops. $2^{\text {nd }}$ Eds. Vol. 1. Naya Prakash. 206 Bidhan Sarani, Kolkata. India. pp. 35-39.

Sing AK, Singh M, Singh AK, Singh R, Kumar S and Kalloo G (2005) Genetic diversity within the genus Solanum (Solanaceae) as revealed by RAPD markers. Curr. Sci. 90: 711-714.

Whalen MD (1984) Conspectus of the species group in Solanum subgenus Leptostemonum. Genet. Herb. 12: 179-282.

Williams JGK, Kubelik AR, Livak KJ, Rafalski JA and Tingey SV (1990) DNA polymorphisms amplified by arbitrary primers are useful as genetic markers. Nucleic Acids Res. 18: 6531-6535.

Yeh F, Yang C, Boyle TBJ, Ye ZH and Mao JX (1999) POPGENE, the user-friendly shareware for population genetic analysis. Molecular Biology and Biotechnology Centre, University of Albetra, Canada. 